\title{
La escuela: territorio de paz. Una apuesta para el posacuerdo
}

\author{
Soñamos con una escuela que, por ser seria, se dedique \\ a la enseñanza de manera competente, pero, que dedicada, \\ seria y competente a la enseñanza, \\ sea una escuela generadora de alegría. \\ Paulo Freire
}

No hay lugar para dudar que el acuerdo con la insurgencia armada en Colombia constituye uno de los mayores focos de atención y de interés para la sociedad, más allá de las fronteras de nuestra patria. Todos los organismos deliberativos donde confluyen los países de la orbita terrestre se han pronunciado en apoyo a este acuerdo, con las debidas observaciones, claro está. Extrañamente en nuestro país este acontecimiento no ha alcanzado el mayor y contundente grado de consenso entre los nacionales, quienes somos los mayormente afectados y quienes deberíamos ser los mas interesados en resolverlo por la vía del diálogo y la concertación; no obstante, estamos lejos alcanzar este logro necesario para el futuro de las nuevas generaciones de nacionales y por esa misma razón hay que insistir y persistir.

Tampoco hay dudas cuando afirmamos que ningún ente nacional ha sido ajeno o ha permanecido indiferente frente a este acontecimiento. Desde los gremios de la producción industrial y agropecuaria, el comercio, los banqueros, los transportadores, los urbanizadores, las fuerzas armadas activas y en retiro, los partidos políticos en sus distintas tendencias ideológicas, los sindicatos, las universidades hasta los académicos-intelectuales se han pronunciado al respecto y se prestan a definir su futuro teniendo como referente los acuerdos de paz; la escuela no podía ser la excepción.

Cuando Fecode-Ceid levanta la consigna "la escuela, territorio de paz", es el mejor reconocimiento a esta institución, pues ha sido epicentro y victima de esta guerra fratricida que ha azotado nuestra patria por mas de seis décadas. Es un reconocimiento que este territorio y los procesos que allí se desarrollan han estado permeando por los avatares del conflicto social y político; que su devenir está distante de aquella visión romántica y humanista en la que nació la escuela siglos atrás; que los sujetos que por ella transitamos en condición de maestro, directivo-docente o estudiante hemos sentido en carne propia el rigor de la guerra; que los procesos de enseñanza y aprendizaje, razón de ser de esta entidad, no han escapado a los designios e intereses de quienes la promueven, por múltiples razones, desde las más altruistas hasta las mas banales.

Si levantamos la consigna de convertir a la escuela en territorio de paz es porque ella ha sido también territorio de guerra. De esa guerra invisibilizada provocada por el hambre de nuestros niños y niñas que circulan por los salones de nuestras escuelas y colegios en los distintos niveles, tanto de las zonas urbanas como rurales. La misma guerra que en otros espacios extraescolares destruye la unidad y fortaleza familiar y las condena a los vicios sin límites ni control que promueve una sociedad de consumo. La guerra que les niega a nuestra gente empobrecida las posibilidades de una salud de calidad y oportuna, de una vivienda con sus servicios que dignifique su condición humana. La escuela es también el epicentro de esta otra guerra que también debemos resolver quienes transitamos por ella como maestros, con el aporte de quienes hoy hacen esfuerzos por 
dejar las armas como instrumento para alcanzar una meta y, especialmente, el Estado, representado hoy por un gobierno que se las jugó por la paz, lo cual hay que valorarlo, pero también convocarlo a que cumpla con los unos y con la escuela.

Hacer de la escuela un territorio de paz es una perspectiva que se materializa si logramos construir un país como territorio de paz. Esto porque en la escuela se viven los momentos y dinámicas que se desarrolla en la sociedad que le sirve de marco y porque la escuela es un órgano de esa sociedad en crisis. Asumir la escuela como territorio de paz no pasa por negar el conflicto, derivado de una sociedad que se construye día tras día, en medio de los mas diversos intereses. Si nos reconocemos como sociedad pluriétnica y multicultural, es natural reconocer las tensiones, los encuentros y desencuentros que provocan los avatares de la lucha por la vida. Reconocer la naturaleza conflictiva de la condición humana nos pone en condiciones de búsqueda de aquellos mecanismos que nos permitan superarlo, siempre acudiendo a la palabra, al dialogo, a la concertación, al consenso, amparados en la idea de ceder ante el mejor argumento.

Concebir la escuela como territorio de paz pasa por superar el debate mercantilista respecto de los estándares, las competencias, los derechos básicos de aprendizajes o el índice sintético de calidad, al cual nos han llevado organismos internacionales interesados en reducir la educación a un campo de formación para el trabajo y la producción mercantil. Hablar de calidad de la educación pasa por la exigencia de calidad de vida digna para las comunidades educativas en las escuelas, colegios y universidades del país.

Apoyados en los documentos de la Fecode-Ceid, queremos dejar en claro el para qué hacer de la escuela un territorio de paz, como parte del aporte del magisterio colombiano y de ellos, el guajiro, a la consolidación del posacuerdo:

- Para reconstruir la memoria histórica de la escuela con relación a la guerra y la violencia, visibilizar los efectos que ha padecido; cómo y por qué ha subsistido, cómo se la jugado para que, en medio de las armas, no se agote la pedagogía, ni las posibilidades de realizar-se. Para no agotar la esperanza de hacer una escuela para una Colombia sin guerra y con justicia social. Para aprender de la historia y no repetirla y para apostarle a realizar una historia para la paz.
- Para construir la escuela capaz de formar las nuevas generaciones de colombianos y colombianas, en una cultura y mentalidad de paz y para la paz, en una conciencia critica del buen vivir, la defensa de los bienes comunes y el respeto a los derechos humanos.

- Para posicionar la necesidad de la paz en el territorio de la escuela y mas allá de ella, y que esta se transforme en un proyecto educativo cultural de una sociedad que se refunda en una autentica democracia, en la justicia social, los derechos individuales y colectivos, en el respeto y valoración de lo diverso, en la valoración de la dignidad de lo humano y la promoción de una paz integral, sustentada en el bien individual y el común.

- Para hacer de la escuela un territorio fértil para el reconocimiento y promoción de la pedagogía como saber fundante del maestro-enseñante y la expansión de expresiones donde se cultiva el saber pedagógico y la critica constructiva, como el Movimiento Pedagógico, el Proyecto Educativo y Pedagógico Alternativo, la Expedición Pedagógica, los Proyectos Pedagógicos de Aula, las Redes de Maestros, etc.

En armonía con los acuerdos de paz, a la escuela hay que reconocerla como víctima del conflicto, en consecuencia debe ser sujeto de reparación colectiva, por la extensa deuda que el estado colombiano tiene con los miembros de las comunidades educativas, en particular los maestros y maestras, por quienes nos atrevemos a hablar. Tal proceso de reparación, que incluye también el compromiso de no repetición ni olvido, pasa por:

- El mejoramiento de las condiciones de vida de maestros y maestras, el reconocimiento de su condición de sujeto intelectual, ético y político, responsable del principal papel de la escuela: la enseñanza.

- Articular y mejorar la relación de la escuela con la sociedad, hacer más difusas las fronteras de la escuela, diría Antanas Mockus, en procura de construir una sociedad con un proyecto cultural de paz; fundado en el saber como bien universal y humano.

- Materializar un proyecto de escuela fundado en la democratización de la vida institucional que recoja el interés y las expectativas de todos los miembros la agencian: Estado, sociedad y comunidad educativa. La democratización de la vida institucional pasa por someter al análisis 
y discusión los manuales de convivencia, en la dinámica que recojan las expectativas de todos los miembros de las comunidades educativas y de que consulten derechos constitucionales/ legales vigentes.

- La definición y construcción de políticas públicas en educación, planteadas desde la idea de reconocerla como un derecho fundamental, como bien común y como patrimonio de la humanidad. Si los acuerdan perfilan la creación de otra sociedad en Colombia, la escuela como territorio de paz promueve la creación de otra escuela para otra educación.

- Superar el espíritu empresarial/mercantil al que han llevado acciones pedagógicas en la escuela, amparado en las políticas neoliberales predominantes, con todas las consecuencias conocidas hoy: la negación de la pedagogía como saber del profesional de la educación y la práctica docente, la educación y la enseñanza como un servicio y por tanto sujeto a la comercialización y el mercado, la alienación del maestro de su condición de sujeto ético y político; vaciado de sus funciones como trabajador de un campo intelectual/cultural y limitado a un ser reproductor de ideas y discurso circulantes/dominantes en una sociedad en absoluta descomposición.

- Garantizar a la escuela y al maestro las mejores condiciones para cumplir con su misión. Si la Jornada Única es un logro por alcanzar, esta debe contar con todas las condiciones requeridas para su desarrollo. Tales condiciones incluyen una óptima dotación de material didáctico y la adecuada y oportuna alimentación para niños y niñas, acompañada del transporte escolar, en especial para las zonas rurales.

- Reconocer y aceptar que los países que han sido exitosos en educación, han empezado una larga campaña de formación integral de sus maestros y una adecuada y exigente valoración de la profesión docente. La otra escuela que buscamos debe estar dotada de maestros excelentes en su campo de formación profesional. Al lado de la exigencia de calidad académica esta la exigencia por mejores condiciones de vida personal y familiar para el gremio. Esta tarea exige repensar el estado actual de las normales superiores y las facultades de educación, la política de "ser pilo paga" esta distante de lo que requerimos en materia de formación docente.

Finalmente, la escuela como territorio de paz la proyectamos como una espacio en el que sea posible la vida en auténtica democracia y democracia para convivir en paz. Es la posibilidad que tenemos de construir una escuela con la comunidad y para la comunidad, es una estrategia de reconocimiento de la comunidad como agente vinculable a las luchas por la defensa de la educación pública y de calidad, por su dignificación como seres humanos y por la dignificación de la profesión docente. Una escuela democrática y en paz es la que ofrece fértiles posibilidades para la crítica y la confrontación de ideas, en el marco de la renovación de los manuales de convivencia, los gobiernos escolares y la toma de decisiones y la revitalización de los consejos directivos y académicos institucionales, las personerías estudiantiles y los proyectos educativos institucionales.

No creo que sea demasiado pedir que se haga eco de nuestras voces que son las voces de quienes transitamos los espacios escolares en busca de hacer de la enseñanza una manera de ser profesional de un quehacer, para que otros, nuestros estudiantes, encuentren un camino para ser ellos sujetos que realicen su proyecto de vida. Son las voces que claman por su reconocimiento, su valoración y su oportuna atención.

Que no quepa la menor duda respecto del compromiso de gran parte del magisterio guajiro por hacer de la escuela un territorio de paz, en el marco de un país en paz, de nuestra decisión inquebrantable de estimular para convencer a muchos colegas escépticos con este proceso, de nuestra apuesta por hacer de nuestra profesión un campo de reflexión para una práctica pedagógica de alta calidad y de nuestro espíritu democrático para convivir y concertar con argumentos racionalmente sustentables.

Alfonso José Acuña Institución Educativa Número Dos Maicao, La Guajira, Colombia Correo electrónico: alfonsojota1@gmail.com 